\title{
MATEMÁTICA, LINGUAGEM E TRADUÇÃO ${ }^{1}$
}

\author{
Sundar Sarukkai ${ }^{1}$ \\ 1National Institute of Advanced Studies, Bangalore, Karnataka, Índia
}

\begin{abstract}
Tradução de Rodrigo Bilhalva Moncks²
Alinne Balduino P. Fernandes 2

${ }_{2}^{2}$ Universidade Federal de Santa Catarina, Florianópolis, Santa Catarina, Brasil
\end{abstract}

\begin{abstract}
Resumo: O discurso matemático não é possível sem o vasto uso de uma língua natural. Seus símbolos referem-se, acima de tudo, a termos da língua natural. Seus textos são uma combinação de símbolos, língua natural, diagramas, e assim por diante. Ler esses textos de forma coerente significa estar envolvido na atividade da tradução. A matemática aplicada, assim como a física, muda constantemente de uma linguagem (e cultura) para outra e, portanto, é melhor compreendida no âmbito dos Estudos da Tradução.
\end{abstract}

Palavras-Chave: Discurso Matemático; Linguagem Natural; Símbolos; Estudos da Tradução

\section{MATHEMATICS, LANGUAGE AND TRANSLATION}

\begin{abstract}
The mathematical discourse is not possible without a fertile use of natural language. Its symbols, first and foremost, refer to natural language terms. Its texts are a combination of symbols, natural language, diagrams and so on. To coherently read these texts is to be involved in
\end{abstract}

\footnotetext{
${ }^{1}$ N. dos T.: Sarukkai, Sundar. "Mathematics, Language and Translation". Meta, 46, (4), (2001):664-674. A tradução desse artigo teve autorização do autor, Dr. Sundar Sarukkai, e do editor-chefe da revista Meta, Dr. Georges Bastin. Todas as citações diretas foram traduzidas para o português pelos tradutores.
} 
the activity of translation. Applied mathematics, as in physics, constantly shifts from one language (and culture) to another and, therefore, is best understood within the ambit of translation studies.

Keywords: Mathematical Discourse; Natural Language; Symbols; Translation Studies

A matemática se caracteriza como um discurso singular, tendo em vista seus objetos, suas estratégias e até mesmo a forma como ela utiliza a linguagem. É indiscutível, no entanto, que a singularidade desse discurso não ocorre apenas pelo seu sistema de símbolos privilegiado. A matemática usa símbolos como parte do seu discurso, e cria narrativas elaboradas a partir desses símbolos e operadores. O papel central do signo "=" é também parte fundamental da diferença entre este e outros discursos. Graças à presença profusa de símbolos, a distinção do discurso matemático tem sido erroneamente atribuída a esses símbolos "não-linguísticos", e essa concepção veio a gerar discursos que tentam imitar o matemático apenas se apropriando de indícios de linguagem, sob tentativas de reescrevê-lo em notação simbólica. Como resultado, pode-se dizer que a "matematização" não se baseia apenas na apropriação de equações e técnicas matemáticas; é a relação com a língua, manifestada em seu domínio simbólico, que representa a singularidade do discurso matemático. A partir disso, conclui-se que é possível haver discursos matematizados que não sejam visivelmente simbólicos.

A ênfase no caráter simbólico da matemática traz em si uma rejeição à língua natural (LN), e se faz necessário debater esse assunto mais a fundo. Qual é a relação, então, no nível do discurso e dos textos, entre uma língua natural e uma linguagem baseada em símbolos? Há de fato uma ausência de LN nos textos da matemática? Se a LN está presente, o que ela faz? Wittgenstein comentou sobre a relação entre as línguas naturais e a matemática, e Shanker (cap. 5) salienta alguns desses comentários, ao ressaltar que os argumentos de Wittgenstein sobre a relação entre "prosa" e matemática eram relacionados, em sua maioria, ao papel da Filosofia 
da Matemática. Para Wittgenstein, o problema da prosa no contexto da matemática surge quando conversamos "sobre" um cálculo. A perene dificuldade da conceptualização torna-se visível com a presença de palavras. Shanker sugere que Wittgenstein reconhece que as "traduções de um cálculo para prosa" são traduções "nas quais as evidências são apresentadas através de um meio diferente, que podem 'iluminar' [ou seja, sugerir outra forma de olhar] a importância ou as implicações de uma evidência" (Shanker 206). O embate principal encontra-se na possibilidade de a matemática ser expressa sem se recorrer a palavras, ou se o conteúdo da prosa é indispensável à formulação matemática. Shanker é categórico ao afirmar que “é óbvio que a presença da 'prosa' não é arbitrária nem dispensável” (Shanker 207). Não enxergo um contra-argumento a essa posição.

Se abrir um livro de matemática, você notará uma grande presença de termos de LN (a língua portuguesa será utilizada como exemplo de língua natural a partir de agora ${ }^{2}$ ) no texto. Isso acontece, em parte, e talvez ironicamente, porque ao retirarem-se os cálculos (à exceção dos traços), reduz-se a densidade simbólica do texto. Mas o subtexto da língua portuguesa no texto matemático segue proeminente. Palavras, frases e outras expressões do português são fundamentais na articulação do discurso matemático. Consideremos alguns exemplos de textos de nível avançado, destinados a matemáticos profissionais. A escolha desse exemplo é para enfatizar que o subtexto em português é importante em textos profissionais tanto quanto em semiprofissionais e pedagógicos. Primeiro consideraremos um dos teoremas mais importantes da aritmética, chamado de Teorema Fundamental da Aritmética (Apostol 17):

Teorema Fundamental da Aritmética: todo número inteiro $\mathrm{n}>1$ pode ser expresso como um produto de fatores primos de uma forma única, independentemente da ordem dos fatores.

${ }^{2}$ N. dos T.: No texto de partida, o autor utiliza exemplos em língua inglesa.

Cad. Trad., Florianópolis, v. 40, n 2, p. 410-428, mai-ago, 2020. 
Esse teorema obviamente é uma afirmação "em língua portuguesa", no sentido de que seu significado é derivado do sentido das palavras em português utilizadas na declaração. Há também termos pertencentes à matemática que são escritos em português. Estes incluem "inteiro", "primo", "fatores" e "produto". Todas essas palavras aparecem na língua portuguesa corrente, porém nesse teorema elas têm um significado específico: "primo" refere-se aos números primos, que são distinguidos por uma característica especial (a de serem divisíveis apenas por eles mesmo e por 1); a palavra "fator" se refere à expressão de um número como o produto de outros números, e "produto" em si se refere à multiplicação. Esse é um exemplo simples de um importante teorema da aritmética que é expresso em língua portuguesa e depende dela para sua articulação. Mas, mesmo quando isso acontece, há também restrições ao significado de certas palavras. O próprio teorema é precedido pela definição de cada um desses termos, como "primo". A declaração do teorema não é simbólica, mas restringe as possibilidades semânticas de algumas palavras usadas; portanto, ela é simbólica em sua essência, mas não é expressa simbolicamente. Percebe-se que outras palavras também têm importância na produção de significado desse teorema. A frase "pode ser expresso" não é definida da mesma forma precisa que palavras como "primo" e "fator" foram. Portanto, nossa leitura desses termos é aberta às possibilidades interpretativas, tal como ocorre em português. Essa é uma estrutura típica de uma afirmação matemática. Quando palavras em português são utilizadas, algumas são restritas a um significado específico, mas há também uma grande quantidade de palavras que são usadas da mesma forma que em outros discursos da língua portuguesa. Dessa forma, em uma afirmação matemática, apesar da definição ser refinada para algumas palavras, a pluralidade de significados de outras é mantida. Isso leva a uma justaposição muito interessante.

É importante perceber que, apesar de haver uma restrição de significado em palavras como "primo" e "fator", há, simultaneamente, o desenvolvimento de uma narrativa sobre números primos, de carga semântica rica. Isso sugere que não é a ascensão semânti- 
ca que deve ser considerada, mas sim a difusão semântica, onde há uma transferência horizontal de significado de um domínio a outro.

Os teoremas e resultados que são derivados do teorema acima apresentam um conteúdo simbólico maior. Em todo caso, a redução de palavras para um conteúdo simbólico maior só é possível através das definições e resultados de teoremas precedentes. Esses resultados e definições primários usam o português muito mais do que os seguintes, referentes a eles. Quando vemos um teorema recheado de símbolos, então, cada um desses símbolos derivou todo seu significado de uma ligação com a língua portuguesa. Ou seja, é o português que expressa a matemática primeiro, antes de dar voz aos símbolos.

Matemáticos podem não aceitar facilmente essa visão, já que há uma crença forte nessa comunidade de que as palavras são redundantes e podem sempre ser substituídas por símbolos. As observações de Hadamard sobre a psicologia da matemática são pertinentes nesse contexto. Após mencionar que concorda plenamente com o argumento de Schopenhauer de que "pensamentos morrem no momento que são incorporados por palavras", ele afirma acreditar que isso ocorre não só com as palavras, "mas até mesmo com os sinais algébricos" (Hadamard, 75). Hadamard acrescenta ainda que, no ato criativo, ele próprio trabalha não com palavras, mas com imagens vagas na mente, e é somente no estágio de "verificação" que ele "pode vir a usar sinais algébricos" (Ibid. 82). E complementa: "Quanto às palavras, elas permanecem absolutamente ausentes da minha mente até o momento de comunicar os resultados em forma escrita ou oral" (Ibid. 82). Em seguida, cita outros exemplos de matemáticos que possuem crenças similares sobre o papel das palavras. Como uma exceção, alude a outro matemático famoso, George Polya, que escreveu para Hadamard (Ibid. 84-85):

Eu acredito [...] que a ideia decisiva, que traz a solução de um problema, está muitas vezes ligada a uma palavra ou frase bem colocada. A palavra ou sentença ilumina a situação, dando às coisas, como você diz, uma fisionomia. 
Ela pode preceder por pouco a ideia decisiva, ou segui-la imediatamente; talvez, apareça ao mesmo tempo [...]. A palavra certa, com a sutileza apropriada, nos ajuda a lembrar da ideia matemática, talvez de forma menos completa e objetiva do que um diagrama ou notação matemática, mas de forma análoga $[. .$.$] pode contribuir para a solução na mente.$

Dessa forma, apesar de Polya reconhecer o papel da língua, pode-se ver que ele é cuidadoso e hesitante nesse reconhecimento. Há também uma ambiguidade, já que apesar de dizer que a "ideia decisiva" está "ligada" a uma palavra ou frase, ele especifica que ela deve ser "bem colocada". Apesar de Polya não falar explicitamente sobre a escrita do discurso, mas sim sobre o processo criativo da matemática, suas observações são aplicáveis a ambos os casos.

Consideremos outro exemplo. Apostol, ao descrever grupos matemáticos, escreve sobre uma propriedade destes da seguinte forma: "Para cada 'a' e 'b' em ' $G$ ', há também um 'a.b' em ' $G$ '” (Apostol 129). Isso pode ser reescrito simbolicamente como Aa,b $\in \mathrm{G}$, a.beG. Essa reescrita simbólica remove o conteúdo em língua portuguesa? Não, pois os símbolos foram definidos previamente ao seu uso. Então, antes de podermos escrever de forma simbólica, nós diríamos que "A" representa "para cada" e " $\in$ " representa "pertence a". Nesta notação simbólica, "pertence a" e "em" são sinônimos. Podemos refinar essa ideia mais ainda ao gerar vários símbolos, mas o ponto é que os símbolos matemáticos se referem, antes de tudo, a palavras de uma língua natural. Notamos também as mudanças de significado que aparecem com o uso dessa tradução. Dessa forma, " $\in$ " significa "pertence a", "pertencente a”, e assim por diante. Se retraduzirmos os símbolos de volta ao português, leremos: Para cada "a, b" pertencente a "G", “a.b" (também) pertence a “G”. Este tipo de troca dinâmica entre o texto simbólico e o de língua portuguesa causa constantes deslizes de significado e, portanto, abre o universo semântico do discurso.

A discussão acima sugere que a primeira referência do discurso matemático existe na LN. Essa "sublíngua do português" não se 
configura como um discurso por si; é basicamente uma coleção de palavras e frases dessa língua. Mas essas têm papéis importantes, se não nos cálculos em si, ao menos na abertura das possibilidades semânticas à imaginação criativa ${ }^{3}$. Isso traz também a matemática aos problemas da vida real, dos quais ela se origina em primeiro lugar.

Ao analisarmos qualquer texto matemático, encontraremos alguns termos e frases-chave que ocorrem repetidamente, como "Considerando", "Assumindo", "Supondo", "Nota-se que", "Vem a seguir", "Podemos ver que", e assim por diante. O discurso matemático conta com uma grande quantidade de "nomes" que são identificados e associados a propriedades especiais de números e funções. O português também é usado como recurso retórico. Termos como "nota-se que", "podemos ver que" e assim por diante, reforçam a presença da retórica na escrita. A língua portuguesa parece ser usada como transportadora para esses movimentos retóricos, e ajuda também a introduzir espaços de ambiguidade nos lugares onde movimentos explicitamente metafóricos podem ser feitos. Quando isso acontece, os novos resultados produzidos não são estritamente corretos na matemática, mas podem ser utilizados e refinados de forma a caberem no esquema matemático. Há diversos exemplos disso, onde a matemática foi refinada e tornada mais concisa na física a partir de termos que eram matematicamente imperfeitos.

A presença do português na matemática ocorre através de variadas disciplinas. Considere esse exemplo da topologia: "Um homeomorfismo, ou transformação topológica, é um mapeamento individual contínuo de um espaço topológico $\mathrm{X}$ sobre um espaço topológico Y, de forma que f -1 também é contínuo" (Kelley 87); essa declaração define "homeomorfismo". As palavras em português aqui funcionam literalmente como nomes e, sendo nomes, não têm definições plurais, mas sim fixas. Como é costume nesses casos, a natureza fixa dos nomes se dá em referência a algo que é

${ }^{3}$ N. do A.: Citando Shanker (209): "Wittgenstein prontamente concordou que [...] conceitos verbais desempenham um papel integral no desenvolvimento de ideias matemáticas".

Cad. Trad., Florianópolis, v. 40, n 2, p. 410-428, mai-ago, 2020. 
nomeado. Aqui há uma simulação de nomes, no sentido de eles não estarem disponíveis para participação na língua em que são escritos (português). Mas o discurso não pode ser escrito, comunicado e levado para a matemática sem a presença do texto escrito em português. Isso talvez sugira que as palavras de língua portuguesa são usadas como símbolos gráficos desprovidos de significados que difiram daqueles derivados da nomeação, mas isso também não está correto. Veja o uso de palavras como "contínuo", um termo central na análise. Embora exista um significado específico para "contínuo", ele não pode ser substituído por outra palavra vazia de significado, porque a matemática se apega à imagem semântica inspirada pela palavra "contínuo", na forma que ela ocorre em uma fala que não é matemática. Esse apego ao domínio semântico do português, mas com a reescrita do discurso de uma maneira que simula a rejeição da pluralidade, por meio de definições "precisas", é a principal característica do discurso matemático. Ele simula uma restrição de sentido, apesar de sorrateiramente encorajá-lo! Essa mediação, o próprio ato de tradução, é bivalente.

Buscar a essência do significado das palavras já as coloca em paridade com os símbolos. Portanto, as palavras em português aqui imitam o roteiro da linguagem, mas não pertencem estritamente à cultura dessa língua. A escrita desse discurso busca apagar a língua, mas mantém traços dessa rasura. Ao fazer isso, permite-se que a palavra, reduzida a um único significado, seja também incorporada a um jogo de significantes em um discurso diferente, com um conjunto diferente de regras.

Essa, então, é a controvérsia: os símbolos usados na matemática se originam com a ajuda e em relação às palavras da língua natural. Estes símbolos se referem, antes de qualquer coisa, às palavras. O processo de simbolização não acrescenta novos significados à palavra cujo símbolo está associado; na verdade, ao defini-la estritamente, reduz os múltiplos significados da palavra. Então o que os símbolos fazem que as palavras não podem fazer? A simbolização permite que as operações sejam executadas nos símbolos e, nesse processo de manipulação, construção e execução, cria novas ex- 
pressões. Os próprios operadores trabalham sob a força reguladora do sinal " $="$.

Mesmo nessa atividade, contudo, nunca estamos livres de cair nos perigos da riqueza expressiva da LN. Se a simbolização pode ser vista como uma tentativa de reduzir os significados possíveis de uma palavra, a complexidade do discurso matemático é uma prova de que ela falhou nessa missão, pois no reino da imaginação, na mente do matemático, a presença de termos da LN não permite um afastamento da pluralidade semântica e da força metafórica de seu enunciado. Pode-se sempre transferir essas imagens de volta ao simbolismo. A disciplina da matemática não é inerente à negação de novas imagens; pelo contrário, elas são bem-vindas, desde que os novos participantes estejam de acordo com os princípios já aceitos. Assim, a imaginação metafórica é uma obrigação; a ambiguidade das palavras é maravilhosa, desde que aconteça antes do processo simbólico.

A discussão acima sobre a ligação entre a matemática e a língua natural flerta constantemente com a ideia de tradução, mesmo que essa imagem não seja explicitada. A ênfase na ideia de escrita, que torna o discurso matemático possível e original, naturalmente nos leva a considerar a questão da tradução em relação à matemática. A ligação entre a tradução e a matemática, sempre oculta, precisa ser explicada, pois nos informa que a atividade matemática é de fato uma escrita matemática, e que essa escrita tenta esconder a noção de tradução, apesar de dever muito a ela. É essa correspondência entre matemática e tradução que precisa ser examinada.

É compreensível que a matemática busque se distanciar da ideia de tradução. Muitos fatores sugerem isso. Primeiramente vem a ênfase excessiva na verdade, que ignora o fato de que o prazer de escrever a matemática em cálculos gera uma sedução que ultrapassa a legitimidade do resultado final. A atividade é intensamente satisfatória e o resultado final é um bônus. Em segundo lugar, vem a suspeita que se tem da linguagem.

A matemática carrega essa suspeita ao extremo, onde palavras são literalmente reduzidas a pontos linguísticos - em alfabetos. A 
tradução dobra a dose de suspeita, pois sua atividade inspira pouca confiança e respeito, mesmo entre aqueles cujas preocupações estão dentro dos limites da LN, em grande parte porque é vista como derivativa e incapaz de capturar a expressão original. A matemática não considera a LN como original no que diz respeito ao mundo platônico. Sob esse ataque duplo, não é estranho que haja pouco reconhecimento da ligação entre tradução e matemática.

Mas a matemática é escrita. A atividade pela qual a matemática cria seus alfabetos destaca seu primeiro contato com a LN: ela reduz a medida gráfica das palavras para grafemas. Esse movimento é uma escrita da escrita, é reescrever o que já foi escrito. A atividade da tradução é a que melhor descreve essa "escrita da escrita". Acima de tudo, a tradução é a escrita do já escrito e, acima de tudo, a escrita matemática é um ato tradutório.

As teorias tradicionais da tradução focam muito no significado. As palavras são vistas como marcas que ocupam o lugar de um significado maior. Ao fazer esse movimento, esquece-se do impulso que gerou as palavras como marcas gráficas no papel. Antes de entrarmos no domínio do significado, entramos no mundo da percepção do escrito, na visão dos rabiscos em uma folha. A tradução, nesse nível, é semelhante ao traçado. O que fazemos, ao traçar por cima de outro desenho, se não aprender a reconstruir marcas gráficas? A marca é o original, e toda tentativa de reprodução é uma transferência, nesse sentido. A matemática, ao iniciar com a redução da marca-palavra para a marca-alfabeto, expressa claramente esta atividade: é a transferência que primeiro sugere a possibilidade de tradução.

O domínio simbólico é a linguagem, baseada em convenções e regras. Esses símbolos geram significado, criam textos e discursos. Criam, também, narrativas ricas sobre o mundo simbólico. Porém, como discutido anteriormente, o mundo simbólico é gerado por meio de uma referência ao mundo da LN. A língua natural está envolvida na criação dessa linguagem, mas é considerada inadequada como parceira de seu discurso. Então a LN deve ser invisibilizada, apesar da escrita do texto trair esse movimento e torná-la visí- 
vel- excessivamente visível. O recurso, então, é negar qualquer conteúdo substancial a ela. A matemática ocorre em uma dualidade metafísica: o mundo simbólico é sua mente e o mundo escrito, tanto em termos de LN quanto nos textos ocultos do cálculo, é o "corpo" do discurso. Em tal cenário, como pode haver a possibilidade de tradução? Ao invocar o nome da tradução, invocamos e criamos a imagem da LN como original, e a linguagem simbólica não apenas como uma forma abreviada dela, mas uma forma traduzida. Poderia existir uma blasfêmia maior que essa? Mas existe verdade maior?

Como expandir essa questão? A LN não pode ser aceita (por aqueles que veem a matemática inteiramente em termos de lógica e platonismo) como o original do qual o texto matemático surge através de um tipo de tradução, até porque a matemática supostamente se refere a um mundo platônico. Diferentemente de outros discursos, o matemático não apenas nega qualquer ligação com a LN, como também critica ferozmente a ambiguidade e a confusão inerentes a ela. Logo, todos os traços dessa ligação devem ser apagados. Mas só é possível fazê-lo através da escrita, e é essa escrita que retoma a ligação e sugere que a linguagem da matemática é, em si, uma tradução da língua natural.

Mais do que outras línguas em que a tradução está envolvida, é a ligação entre a $\mathrm{LN}$ e a matemática, exibida tanto na matemática "pura" quanto na "aplicada", que se aproxima mais da temática da tradução de Walter Benjamin em relação ao parentesco entre língua e língua pura ${ }^{4}$ É a relação entre as línguas que torna a tradução possível e, na verdade, pode ser vista como uma iniciação da tradução. O parentesco entre línguas não é derivado de origens comuns, ou roteiros comuns, ou de relação entre famílias. A possibilidade da tradução em si é encontrada na "relação recíproca entre línguas" (Johnston 44). A ideia de parentesco é naturalmente inspirada por essa interação entre matemática e LN. O parentesco entre línguas, para Benjamin, não gira em torno da semelhança

${ }^{4}$ N. do A.: Ver Walter Benjamin (1992) e Andrew Benjamin (1989).

Cad. Trad., Florianópolis, v. 40, n 2, p. 410-428, mai-ago, 2020. 
entre elas, mas sim "da intenção subjacente a cada língua como um todo - uma intenção, contudo, que nenhuma língua pode atingir sozinha; é percebida apenas pela totalidade das intenções que se complementam" (Ibid. 44).

Fica claro que a matemática como língua não se esgota apenas no conteúdo simbólico, mas também na necessidade da LN de "suplementá-la”. No caso da matemática, o parentesco torna-se visível no nível da própria marca gráfica, e se torna mais visível ainda na referência dos símbolos às palavras da LN. Associada ao tema do parentesco entre línguas está a ideia de língua "pura”, que é sem dúvida um problema nos escritos de Benjamin, não menos por sua associação a doutrinas teológicas ${ }^{5}$. Mas sua articulação incompleta da língua pura ressoa intimamente com a visão de muitos da língua matemática, tida por cientistas e matemáticos. Como Johnston observa: "se há uma língua da verdade, ou uma língua verdadeira, Benjamin afirma, então é essa 'língua pura'” (Johnston 44). Para Benjamin, a noção de língua pura surge no contexto da tradução; para a ciência e a matemática, surge no contexto de sua intraduzibilidade! Para os que propõem essa ideia, a matemática é uma língua privilegiada por ser uma língua que fala a verdade. Até mesmo a natureza é vista como escrita na língua da matemática. As alegações de verdade na matemática, o rigor das provas e as dificuldades do cálculo visam privilegiar a matemática como a língua da verdade. E se olharmos para o que está em jogo nessa noção de verdade, é a intraduzibilidade dela, enquanto, ironicamente para Benjamin, a ideia de "língua pura" envolve a possibilidade de tradução entre diferentes línguas. E o que há de único na matemática? É a inexpressividade em qualquer outra língua; a impossibilidade de traduzi -la para outras línguas. Portanto, nesse contexto, o ponto decisivo da matemática, sua reivindicação de fama em contraste a outras línguas, é o seguinte: a matemática tenta continuamente negar a tradução. Se não fosse esse o caso, ela poderia ser sempre traduzível em outras línguas e, portanto, seria vista ela mesma como uma língua

${ }^{5}$ N. do A.: Nesse contexto, ver Johnston (1992), de Man (1986) e Derrida (1985).

Cad. Trad., Florianópolis, v. 40, n 2, p. 410-428, mai-ago, 2020. 
natural. Mas o discurso da matemática é tal que trai essa tentativa de se tornar intraduzível. Por que mais um discurso seria escrito e apresentado de maneira tão excludente? Por que mais os membros da comunidade teriam que seguidamente provar seu valor não apenas em sua expressão criativa, mas também aprendendo a ler seus textos escrevendo-os simultaneamente? Por que a matemática toma como virtude sua exclusividade? Seria apenas para mantê-la fora da órbita da tradução para outras línguas?

A própria escrita matemática não permite que essa declaração seja incontestada. $\mathrm{O}$ que esse discurso reflete é que as duas línguas (e também o uso de diagramas, figuras e assim por diante) que constituem a matemática habitam diferentes esferas culturais. A língua e os costumes discursivos dessas duas línguas são aparentemente distantes. Mas uma boa tradução responde ao movimento de uma cultura à outra sem "majorização"6. A própria habilidade de permitir que símbolos falem por palavras, passando por operações e cálculos e transformações e então voltando a falar por outras palavras, mostra a inerência da tradução na criação do discurso matemático. Considero aqui o comentário de Paul de Man sobre o artigo de Benjamin, incisivo e particularmente esclarecedor na compreensão da "tensão essencial" que permeia a matemática e sua relação com as línguas naturais. Paul diz:

O que a tradução faz [...] é sugerir [...] o sofrimento da língua original. Sentimos-nos à vontade na nossa própria língua, sentimos um aconchego, uma familiaridade, um abrigo na língua que chamamos de nossa, na qual pensamos não estarmos alienados. O que a tradução revela é que essa alienação é mais forte em nossa própria língua, que a língua original na qual estamos engajados é desarticulada de um modo que nos impõe uma alienação particular, um sofrimento particular (De Man 84).

${ }^{6}$ N. do A.: Ver Venuti (1998).

Cad. Trad., Florianópolis, v. 40, $\mathrm{n}^{0}$ 2, p. 410-428, mai-ago, 2020. 
A escrita matemática mostra que, como as palavras são locais de pluralidade diferencial, assim também são suas reduções simbólicas. A pluralidade exibida nessas reduções simbólicas, contudo, pertence a um campo totalmente diferente. Números - assim como palavras - não podem ser multiplicados. Mas números, como "9" ou "n", podem. Energia (como palavra) não pode ser diferenciada, mas energia como "E" pode. Velocidade (como palavra) não pode ser adicionada em termos de componentes, mas as velocidades como vetores, podem. E assim por diante. No caso de usar a matemática para dar voz ao mundo, ela se torna uma mistura de mundo, língua e matemática. A tradução continuada de um para outro é tanto fonte de criatividade quanto de confusão.

Há mais duas observações sobre esse "parentesco" entre a matemática e a tradução. Uma é a necessidade de entender a matemática "aplicada" (utilizada na física e cada vez mais em outras disciplinas) através da imagem da tradução. A outra envolve a introspecção no símbolo da igualdade no contexto da tradução. Antes de discutir a primeira, me permito fazer algumas observações sobre a relação entre o sinal de igualdade e a tradução. É sabido que a noção de tradução tem uma associação obrigatória com as ideias de comparação. O que torna os estudos da tradução tão difíceis não é apenas a complexidade das línguas e a indecidibilidade dos textos, mas sim a dificuldade em entender o que a comparação entre os textos, e entre o texto e a língua, poderia significar. Existem dois casos específicos de comparação incorporados no discurso matemático. Um é a noção de transferência, citada anteriormente. Outro é a presença do símbolo " =". " =" é, essencialmente, um agente comparativo. Entre números, funções... textos? O sinal " =" tem sua própria dinâmica e bagagem metafísica ${ }^{7}$. Ele regula o discurso, ao mesmo tempo em que libera sua imaginação. Ele fala com a matemática tanto quanto com a tradução. É o modelo de comparação e, como tal, mostra a complexidade e as armadilhas da própria comparação.

\footnotetext{
${ }^{7}$ N. do A.: Discuti esse assunto mais detalhadamente no artigo inédito intitulado "The Writing of Mathematics".
}

Cad. Trad., Florianópolis, v. 40, $\mathrm{n}^{0}$ 2, p. 410-428, mai-ago, 2020. 
Há também a necessidade de entender a matemática "aplicada" através da imagem da tradução, pelas seguintes razões. Talvez o apoio mais forte à afirmação de que a matemática não é apenas uma linguagem única, mas que também possui uma conexão especial com a "verdade", venha de um lugar melhor articulado como "tese da indispensabilidade". Ligada a Putnam e Quine, essa tese afirma que a existência de entidades matemáticas é fortemente sugerida pela sua indispensabilidade na ciência, através do seu papel indispensável nas explicações científicas do mundo (Field). Essa declaração, essencialmente, afirma a condição de existência dessas entidades como primariamente platônicas. Mas há uma questão maior aqui no nível da linguagem. Essa tese sugere que, em última análise, a crença na matemática como a "língua da verdade" é amplamente dependente do sucesso da ciência. O sucesso da ciência está em sua pretensão de descrever o mundo como ele é e na mostra concomitante de sua descrição através da intervenção tecnológica no mundo. Isso sugeriria, então, que as afirmações matemáticas falam a "verdade", não apenas sobre entidades platônicas, mas também sobre o mundo físico. A reivindicação não é meramente sobre a existência de entidades matemáticas, mas também uma afirmação sobre a verdade no conteúdo de suas expressões. Quando percebemos que a tese da indispensabilidade tem tanto a ver com afirmações epistemológicas quanto com as ontológicas, o salto para a linguagem é imediato. A noção de "aplicada", em particular, implica fortemente um movimento de línguas que habitam diferentes domínios culturais com suas respectivas convenções, regras e significados. Assim, explicar o uso da matemática nas narrativas científicas é primeiramente reconhecer a atividade da tradução que torna possível esse "movimento" entre culturas linguísticas. Precisamos ver a tradução sob a rubrica mais ampla da cultura - "como as línguas expressam culturas, os tradutores devem ser biculturais, não bilíngues" (Lefevere \& Bassnett).

É fácil, então, entender por que a matemática aplicada é uma atividade tradutória. As culturas da física e da química, por exemplo, são muito diferentes da cultura simbólica e calculista da ma- 
temática. Suas línguas, metodologias, narrativas e discursos são todos diferentes. A diferença cultural entre os teóricos e os experimentalistas, como descrita por Galison (1997), é manifestada nas diferentes linguagens (junto a diferentes práticas) usadas por essas comunidades. No caso da matemática e da física, por exemplo, a diferença talvez seja maior. A visão do físico sobre o discurso da matemática é bem diferente da visão do matemático. Físicos geralmente não estão preocupados com os teoremas da existência, como os intricados detalhes da prova de um resultado, e assim por diante. Em grande parte, eles encontram no discurso matemático os resultados dos quais então se apropriam para a construção de modelos matemáticos do sistema físico que estão modelando. Essa apropriação não é apenas uma "tomada", mas sim algo que envolve uma "reescrita" criativa para a linguagem da física. Essa atividade é tradutória e os problemas existentes são similares aos problemas que aparecem na tradução de uma língua para outra. Duhem afirma isso explicitamente:

\begin{abstract}
Assim como seus pontos iniciais e finais, a derivação matemática de uma teoria física não pode ser associada a fatos observáveis, a não ser pela tradução. A fim de introduzir as circunstâncias de um experimento nos cálculos, devemos criar uma versão que substitua a linguagem da observação concreta pela linguagem dos números. Para verificar os resultados previstos pela teoria para o experimento, um exercício de tradução deve transformar o valor numérico em uma leitura formulada em linguagem experimental. Mas a tradução é traiçoeira. Entre os fatos concretos, como o físico os observa, e os símbolos numéricos pelos quais esses fatos são representados nos cálculos de seus teóricos, há uma diferença enorme (Duhem 133).
\end{abstract}

Muitos físicos, em seu uso da matemática, tentam destilar a essência dos resultados matemáticos sem se preocupar com detalhes matemáticos complexos. Não apenas a essência é destilada na for- 
ma de resultados e provas específicos, mas também é traduzida de volta para a linguagem do sistema físico que está sendo modelado. Esse movimento tradutório permite que narrativas novas e férteis se desenvolvam. Devemos lembrar aqui que "a tradução, como todas as (re)escritas, nunca é inocente. Há sempre um contexto no qual a tradução acontece, sempre há uma história da qual o texto emerge e para a qual o texto é transposto" (Lefevere \& Bassnett 11).

Considere o exemplo da simetria. Grupos são as estruturas matemáticas associadas à ideia de simetria na física. Grupos, como estruturas matemáticas, são historicamente anteriores e estavam disponíveis para a articulação dos conceitos modernos de simetria. Mas o modo como essas estruturas são escritas e usadas difere bastante nos discursos da matemática e da física. No caso da simetria, a teoria dos grupos foi traduzida para a linguagem da física. Ao fazer isso, acredita-se que as ideias essenciais são mantidas. Essa crença só é possível porque, historicamente, mantivemos esse tipo de crença na tradução. E agora, com novas interpretações da tradução, tornamo-nos cientes de que é impossível isolar essências que podem ser traduzidas. Isso sugere dois pontos: o primeiro é que a matemática é única porque, de alguma forma, permite que as essências sejam destiladas, isoladas e depois traduzidas e transmitidas. O segundo, caso não aceitemos essa proposta, sugere que talvez a teoria dos grupos não seja a única expressão matemática para a simetria e, além disso, que traduções mais radicais e livres entre a matemática e a física gerarão outras estruturas que descrevam a simetria. A reivindicação dessa última terá de vir da própria física; de uma física que entenda sua atividade através do prisma alternativo da tradução.

Talvez seja apropriado terminar essa discussão com uma referência à visão de Walter Benjamin sobre a diferença entre as línguas e sua conexão com a tradução. Porque apesar de a matemática aplicada viver no limite de duas linguagens, ela habita ambas na íntegra. Uma é a linguagem do mundo simbólico chamada matemática, e a outra é a linguagem do mundo, humano e não humano, usada para expressar, comunicar e discursar. Essas linguagens são, 
sem dúvida, diferentes, mas essa diferença pode ser bem-vinda. Encerro, portanto, com as palavras de Benjamin:

\begin{abstract}
A diferença entre as línguas que a tradução deve, de alguma forma, necessariamente superar não pode e não deve ser suprimida, pois a tradução vive nessa diferença; uma tradução particular será valiosa de acordo com a forma como ela alude à ou dissimula essa diferença, ou, mais positivamente, a revela e acentua (Johnston 46).
\end{abstract}

\title{
Referências
}

Apostol, T. M. Introduction to Analytic Number Theory. Nova Iorque: Springer, 1976.

Benjamin, A. Translation and the Nature of Philosophy: A New Theory of Words. Londres e Nova Iorque: Routledge, 1989.

Benjamin, W. Illuminations. Tradução de Harry Zohn. Londres: Fontana Press, 1992.

De Man, P. The Resistance to Theory. Manchester: Manchester University Press, 1986.

Derrida, J. "Tours de Babel”. In: Graham, J. (Ed.). Difference in Translation. Ithaca: Cornell University Press, 1985.

Duhem, P. The Aim and Structure of Physical Theory. Nova Iorque: Atheneum, 1974. 
Field, H. Realism, Mathematics and Modality. Oxford: Blackwell, 1989.

Galison, P. Image and Logic. Chicago e Londres: University of Chicago, 1997.

Hadamard, J. The Mathematician's Mind. Princeton: Princeton University Press, 1996.

Johnston, J. "Translation as Simulacrum". In: Venuti, L. (Ed.). Rethinking Translation. Londres e Nova Iorque: Routledge, 1992.

Kelley, J. L. General Topology. Nova Iorque: Van Nostrand Company, 1955.

Lefevere, A.; Bassnett, S. "Proust's Grandmother and the Thousand and One Nights". In: Bassnett, S.; Lefevere, A. (Eds.). Translation, History and Culture. Londres e Nova Iorque: Pinter Publishers, 1990.

Shanker, S. G. Wittgenstein and the Turning-Point in the Philosophy of Mathematics. Londres e Sydney: Croom Helm, 1987.

Venuti, L. The Scandals of Translation. Londres e Nova Iorque: Routledge, 1998.

Recebido em: 18/12/2019

Aceito em: 14/03/2020

Publicado em maio de 2020

Sundar Sarukkai. E-mail: ssarukkai@gmail.com.

Rodrigo Bilhalva Moncks. E-mail: rodrigomoncks@gmail.com ORCID: https:// orcid.org/0000-0002-8503-874X

Alinne Balduino P. Fernandes. E-mail: alinne.fernandes@ufsc.br ORCID: http:// orcid.org/0000-0003-0979-6036 